\title{
Características qualitativas de produtos elaborados com carne de frango pálida e normal
}

\author{
Qualitative characteristics of products produced with pale and normal broiler chicken meat
}

\author{
Claudia Marie KOMIYAMA ${ }^{1 *}$, Ariel Antonio MENDES ${ }^{1}$, Sabrina Endo TAKAHASHI ${ }^{1}$, \\ Joerley MOREIRA ${ }^{2}$, Hirasilvia Borba Alves BORBA ${ }^{3}$, Fábio Roberto LEONEL ${ }^{3}$, \\ Roberto de Oliveira ROÇA ${ }^{4}$, Ibiara Correia Lima Paz ALMEIDA ${ }^{5}$, Augusto Balog NETO
}

\begin{abstract}
Resumo
Foram elaborados hambúrgueres e filés empanados com peitos de frango pálidos e normais e foram realizadas as seguintes análises de qualidade: cor, Perda de Peso por Cozimento (PPC), cisalhamento, Encolhimento por Fritura (EF), TBA, avaliação microbiológica e sensorial para os hambúrgueres, e TBA, análise microbiológica e análise sensorial para os filés empanados. As amostras de hambúrgueres elaboradas não diferiram significativamente $(\mathrm{p}>0,05)$ nos parâmetros de coloração, EF, PPC e análise microbiológica e sensorial. Para análise de força de cisalhamento, houve diferença significativa $(\mathrm{p} \leq 0,05)$ entre os hambúrgueres no período de 7,60 e 120 dias, sendo que os hambúrgueres elaborados com carne pálida (1,92; 1,31 e 1,46, respectivamente) apresentaram as menores médias quando comparados com os de carne normal $(2,34 ; 1,85$ e 1,73, respectivamente). Na análise de TBA, as amostras elaboradas com carne pálida também tiveram os maiores resultados com 90 a 180 dias de estocagem $(5,28 ; 7,78 ; 8,89 ; 5,02)$ quando comparadas às de carne normal $(2,62 ; 7,05 ; 8,08 ; 3,89)$. Para os filés empanados, não foram encontradas diferenças significativas $(p>0,05)$ entre a elaboração com carne de coloração normal e pálida para os parâmetros avaliados. Estes resultados demonstram que a carne pálida pode ser utilizada para a elaboração de produtos industrializados sem causar prejuízos em sua qualidade.
\end{abstract}

Palavras-chave: cor; peito de frango; TBA; industrializados.

\begin{abstract}
Chicken hamburgers and steaks coated with breadcrumbs were prepared using pale and normal broiler chicken meat. Analysis of color, cooking loss (CL), texture, meat shrinking (MS), TBA value, microbiological evaluation, and sensorial analysis were performed. Hamburger samples made with pale and normal broiler breast meat did not present differences ( $p>0.05)$ for color, CL, MS, sensorial and microbiological parameters during the storage period evaluated. Regarding texture, some difference ( $\mathrm{p} \leq 0.05)$ was noted between the hamburgers after 7,60 , and 120 days of storage. The hamburgers prepared with pale meat $(1.92,1.31$, and 1.46, respectively) presented the lowest averages compared to those prepared with normal meat $(2.34,1.85$, and 1.73 , respectively). For the TBA analysis, samples prepared with pale meat presented the highest values in 90 and 180 days of storage $(5.28,7.78,8.89$, and 5.02) compared to normal meat $(2.62,7.05,8.08$, and 3.89). For the chicken steaks, no differences ( $\mathrm{p}>0.05$ ) were noted between the products made with normal and pale meat for the TBA, sensorial analysis, and microbiological evaluation during the storage periods studied.

Keywords: color; broiler breast; TBA; industrialized.
\end{abstract}

\section{Introdução}

A avicultura de corte vem sofrendo constantes modificações ao longo dos últimos anos. Uma delas é a comercialização de cortes que é cada vez maior quando comparada à comercialização da carcaça inteira. Outra forma que cresce intensamente é a venda de produtos industrializados como hambúrgueres, empanados e diversos pratos já preparados e semiprontos para o

consumo. Assim, tanto para a venda de partes como de produtos industrializados a qualidade do produto final está diretamente relacionada com a da carne utilizada no preparo.

Portanto, problemas relacionados com a qualidade da carne têm preocupado a indústria processadora. Um destes

Recebido para publicação em 20/8/2007

Aceito para publicação em 3/1/2009 (002573)

Departamento de Produção Animal, Faculdade de Medicina Veterinária e Zootecnia, Universidade Estadual Paulista - UNESP, Fazenda Lageado s/n, CP 560,

CEP 18618-000,Botucatu - SP, Brasil,E-mail: claudiamarie@fmvz.unesp.br; arielmendes@fca.unesp; saendosp@yahoo.com.br

${ }^{2}$ Departamento de Zootecnia, Faculdade de Ciências Agrárias, Universidade Federal dos Vales do Jequetinhonha e Mucuri - UFD, Campus II, Rodovia MGT 367, Km 583, 5000, Alto da Jacuba, CEP 9100-000, Diamantina - MG, Brasil, E-mail: joerley@fca.unesp.br

3 Departamento de Tecnologia, Faculdade de Ciências Agrárias e Veterinárias, Universidade Estadual Paulista - Unesp, Rua Prof. Paulo Donato Castellane, CEP 14884-900, Jaboticabal-SP, Brasil,E-mail: hiras@fcav.unesp.br; leonel@fcav.unesp.br

${ }^{4}$ Departamento de Gestão e Tecnologia Agroindustrial, Faculdade de Ciências Agronômicas, Universidade Estadual Paulista - UNESP,

Fazenda Lageado s/n, CP 560, CEP 18618-000, Batucatu - SP, Brasil, E-mail: robertoroca@fca.unesp.br

${ }_{5}$ Departamento de Produção Animal, Faculdade de Medicina Veterinária e Zootecnia, Universidade Estadual Paulista - UNESP, Fazenda Lageado s/n, CP 560,

CEP 18618-000, Botucatu - SP, Brasil, E-mail: ibiara@fca.unesp.br

${ }^{6}$ Zootecnia da Faculdade de Medicina Veterinária e Zootecnia, Universidade Estadual Paulista - UNESP, Fazenda Lageado s/n, CP 560,

CEP 18618-000, Botucatu - SP, Brasil, E-mail: gutobalog@fmvz.unesp.br

${ }^{*}$ A quem a correspondência deve ser enviada 
problemas é a anomalia do PSE que é originário das iniciais das palavras da língua inglesa Pale, Soft e Exudative que, em tradução literal, significa carnes com características pálida ou amarelada, flácida ou mole e exsudativa ou molhada, respectivamente. Na prática, é o resultado das condições de manejo ante-mortem mal conduzidos e estressantes a que são submetidos os animais, provocando um rigor mortis acelerado. Explica-se o fenômeno pela combinação de baixo $\mathrm{pH}$, em geral menor do que 5,8 com elevada temperatura muscular, acima de $35{ }^{\circ} \mathrm{C}$, resultando na desnaturação das proteínas, provocando, em consequência, o surgimento da carne amaciada, sem aderência e descolorida, com propriedades funcionais comprometidas. Isto ocorre em função de uma rápida transformação metabólica do glicogênio em ácido láctico, alcançando $\mathrm{pH}$ final antes do resfriamento da carcaça, o que faz com que a carne se torne pálida.

Esta carne PSE, bastante estudada em suínos e perus, mas pouco estudada em frangos de corte, é conhecida por comprometer as principais propriedades funcionais da carne, como a capacidade de retenção de água e o $\mathrm{pH}$ final, o que pode resultar em produtos industrializados de baixa qualidade. No entanto, a qualidade da matéria-prima utilizada para o preparo destes produtos é essencial para um perfeito rendimento do produto final.

Assim, o pH do músculo tem sido associado com numerosos outros atributos de qualidade da carne, incluindo maciez, capacidade de retenção de água, perdas por cozimento, suculência e estabilidade microbiana. Allen et al. (1997; 1998) mostraram que variações na cor da carne do peito, podem ser devido, primeiramente, aos efeitos do $\mathrm{pH}$, o que, posteriormente, afeta a vida útil da carne do peito, desenvolvimento do odor, umidade durante a marinação, perdas de exsudato, capacidade de retenção de água e perdas por cozimento.

Em suas pesquisas com carne de peru, Barbut (1993) encontrou correlação entre a medida da cor, $\mathrm{pH}$, capacidade de retenção de água e textura, sugerindo a análise da cor pelo Sistema Hunter $\mathrm{L}^{\star} \mathrm{a}^{\star} \mathrm{b}^{\star}$, como uma forma rápida e não destrutiva de distinguir a carne PSE. Em continuidade, McCurdy et al. (1996) e Sosnicki et al. (1998) também encontraram a existência de uma relação entre o valor $L^{*}$ e a capacidade de retenção de água. Desta forma, quanto maior for o valor de $L^{*}$, menor será a capacidade de retenção de água e o peito exibirá uma textura mais macia. Amostras do músculo do peito com valor de $\mathrm{L}^{\star} \geq 49$ apresentam pobre capacidade de retenção de água, o que pode servir para classificar a ocorrência de carne PSE em frangos de corte (Barbut, 1997). Com esta análise, os processadores podem, com a sua matéria-prima disponível, determinar qual sua melhor aplicação, a fim de se obter distintos produtos, dentro de seus requerimentos de qualidade (Barbut, 1998).

Diante dos fatos apresentados anteriormente, este trabalho teve como objetivo avaliar as características de qualidade dos produtos industrializados com carne de peito pálida e normal de frangos de corte e verificar se esta carne pálida pode ser destinada à elaboração de produtos processados sem causar prejuízos na qualidade do produto final.

\section{Material e métodos}

Neste ensaio, foram obtidos 280 peitos pálidos e normais em abatedouro comercial situado no município de Pereiras-SP. Foram utilizados 100 peitos para produção de hambúrgueres e 180 peitos para produção de empanados. Os peitos foram selecionados de acordo com uma avaliação de cor, com uso do colorímetro portátil, considerando que os valores de $\mathrm{L}^{*}$ (luminosidade) acima ou igual a 49 caracterizavam carne pálida e os valores entre 43 e 48, carne normal. Após seleção dos filés de peito, estes foram transportados para o Centro de Tecnologia de Carnes (CTC) no Instituto de Tecnologia de Alimentos (ITAL) na cidade de Campinas. Após 24 horas post-mortem, procedeuse ao processamento do hambúrguer e do filé empanado.

\subsection{Ensaio 1: Elaboração de hambúrgueres com carne pálida e normal}

Os hambúrgueres de carne de peito foram produzidos de acordo com metodologia de processamento utilizada normalmente na indústria. As amostras de carne e pele de frango foram previamente congeladas em freezer a $-17^{\circ} \mathrm{C}$ por aproximadamente 16 horas, moídas em disco com furos com diâmetro de $22 \mathrm{~mm}$ (carne) e $3 \mathrm{~mm}$ (pele) e misturadas com os ingredientes em misturador com disco de $8 \mathrm{~mm}$ de diâmetro. Os hambúrgueres apresentavam a seguinte composição: 80,35\% de carne, 7,5\% de pele de frango, $1,0 \%$ de condimentos para hambúrgueres, $10,0 \%$ de água, $0,5 \%$ de sal, $0,25 \%$ de tripolifosfato de sódio, $0,15 \%$ de cebola pó e $0,25 \%$ de antioxidante. Para esse produto, a carne de peito pálida, após picada, moída e homogeneizada, foi incluída na proporção de $0 \%$ e $100 \%$.

Em seguida, a massa foi enformada e os hambúrgueres prontos foram congelados em armário criogênico e armazenados em freezer a $-18{ }^{\circ} \mathrm{C}$, para avaliação de sua vida útil. As amostras foram analisadas com 30, 60, 90, 120, 150 e 180 dias de armazenamento, sendo que, nessas ocasiões, foram avaliadas as seguintes características: cor objetiva, valor TBA, perda de peso por cozimento, encolhimento por fritura, força de cisalhamento e análise sensorial com provadores para avaliar a qualidade final dos produtos.

A cor dos hambúrgueres foi determinada nas amostras cruas através do colorímetro Chroma Meter CR-300 (Konica Minolta), no sistema CIELab, em triplicata, em que foram avaliados os parâmetros $\mathrm{L}^{\star}$ (luminosidade), $\mathrm{a}^{\star}$ (teor de vermelho) $\mathrm{e} \mathrm{b}^{\star}$ (teor de amarelo) (Van LAACK et al., 2000).

A análise de valor TBA foi avaliada conforme metodologia proposta por Tarladgis et al. (1960), Squires et al. (1991) e Wincke, (1970).

$\mathrm{Na}$ análise de encolhimento por fritura, foram utilizados hambúrgueres congelados e, com o auxílio de um paquímetro, foram realizadas medidas do diâmetro dos hambúrgueres crus e cozidos e, pela diferenças destas mensurações, determinou-se a porcentagem de encolhimento por fritura.

Para a análise de perda de peso por cozimento, as amostras foram cozidas em chapa metálica aquecida até a temperatura interna do hambúrguer atingir $82{ }^{\circ} \mathrm{C} e$, por diferença de peso 
antes e após o cozimento, se obteve a porcentagem de perda de peso por cozimento (HONIKEL, 1987).

Para a análise de força de cisalhamento, foram utilizadas as mesmas amostras da análise de perda de peso por cozimento, sendo utilizadas cinco amostras por tratamento. Cada amostra, após cozida, foi cortada em cinco paralelepípedos de $2 \times 2 \times 3 \mathrm{~cm}$ (altura, largura e comprimento, respectivamente), os quais foram colocados com as fibras orientadas no sentido perpendicular às lâminas da probe Warner-Blatzler acoplada ao texturômetro TAXT 2i (Stable Micro Systems).

A análise microbiológica foi realizada pelo método de plaqueamento em profundidade e incubada a $20^{\circ} \mathrm{C}$ por 48 horas. Posteriormente, procedeu-se à contagem das Unidades Formadoras de Colônias (UFC) por grama da amostra, multiplicando o número de colônias pelo inverso da diluição inoculada (SILVA et al., 1997).

Para a análise sensorial do hambúrguer e do filé empanado, foi utilizado o teste Duo-Trio que tem como objetivo verificar se existe diferença significativa $(\mathrm{p} \leq 0,05)$ entre duas amostras que receberam tratamentos diferentes. Este teste tem o princípio de que o provador é apresentado a uma amostra Referência (R) e a duas amostras codificadas. O provador é então informado de que uma das amostras codificadas é igual à referência, e é solicitado a identificar a amostra igual à referência (STONE; SIDEL, 1985). Este referido trabalho foi submetido à Câmara de Ética em Experimentação Animal, tendo sido aprovado de acordo com os princípios éticos na experimentação animal em 14 de outubro de 2004. A Tabela 1 mostra os dados de faixa etária dos provadores que participaram desta análise sensorial.

\subsection{Ensaio 2: Elaboração de filés empanados com carne pálida e normal}

Os empanados de filé de peito normal e pálido foram produzidos também de acordo com a metodologia de processamento utilizada rotineiramente na indústria. Aos lotes de filés (normal e pálido), foi adicionada solução de marinação a $20 \%$, tendo a seguinte composição: $87 \%$ de carne; $10,3 \%$ de água; $1,5 \%$ de sal; $0,3 \%$ de tripolifosfato de sódio; $0,5 \%$ de açúcar; $0,15 \%$ de alho pó; $0,06 \%$ de cebola em pó; $0,05 \%$ de pimenta branca; 0,05\% de ácido cítrico; e 0,1\% de glutamato monossódico. Cada lote foi submetido ao processo de massageamento por 10 minutos a $20 \mathrm{rpm}$ e deixado descansar por cerca de 14 horas à temperatura de $0{ }^{\circ} \mathrm{C}$ para absorção dos condimentos e aditivos. Após o período de descanso, os filés foram pré-enfarinhados (pré-dust) de forma manual e indivi-

Tabela 1. Faixa etária dos provadores que participaram da avaliação sensorial dos hambúrgueres.

\begin{tabular}{cccccc}
\hline \multicolumn{7}{c}{ Faixa etária } \\
\hline Sexo & \multicolumn{2}{c}{ Homens } & \multicolumn{3}{c}{ Mulheres } \\
\hline & $\begin{array}{c}\leq 30 \\
\text { anos }\end{array}$ & $\begin{array}{c}\geq 30 \\
\text { anos }\end{array}$ & $\begin{array}{c}\leq 24 \\
\text { anos }\end{array}$ & $\begin{array}{c}25 \text { a } 32 \\
\text { anos }\end{array}$ & $\begin{array}{c}\geq 33 \\
\text { anos }\end{array}$ \\
\hline $\begin{array}{l}\text { Número de } \\
\text { provadores }\end{array}$ & 1 & 3 & 7 & 31 & 6 \\
\hline
\end{tabular}

dual. Em seguida, os filés receberam uma cobertura de batter líquido, empanamento automático, pré-fritura automática a $170{ }^{\circ} \mathrm{C}$ e, então, foram congelados em armário criogênico a $-130{ }^{\circ} \mathrm{F}$ por 15 minutos.

Os filés empanados foram armazenados sob temperatura de $-18^{\circ} \mathrm{C}$ e analisados com $7,30,60,90,120,150$ e 180 dias de armazenamento, sendo que, nessas ocasiões, foram avaliadas as seguintes características: valor TBA, análise microbiológica e análise sensorial com provadores para avaliar a qualidade final dos produtos.

A análise sensorial dos filés empanados foi realizada no Laboratório de Análise Sensorial de Alimentos do CTC/ITAL. Para a realização desta análise, foram empregados 39 provadores, utilizando-se o teste Duo-Trio. Na Tabela 2, são apresentados os dados de faixa etária destes provadores. A partir dos dados contidos nesta tabela, observou-se que, dos 39 provadores que participaram deste teste, 30 foram mulheres e 9 homens.

Os resultados foram avaliados, tendo-se dois tratamentos (pálido e normal) e sete períodos de estocagem (0 a 6 meses). Os resultados foram analisados pela Análise de Variância (ANOVA) pelo programa estatístico do SAS (SAS Institute, 1998), utilizando-se o teste $F$ e a análise de regressão.

\section{Resultados e discussão}

\subsection{Hambúrguer de filés de peito de frangos de corte}

Os resultados da cor objetiva (Valor $L^{\star}, \mathrm{a}^{\star} \mathrm{e} \mathrm{b}^{\star}$ ), Encolhimento por Fritura (EF), TBA, Perda de Peso por Cozimento (PPC), Força de Cisalhamento (FC), e análise microbiológica dos hambúrgueres elaborados com carne de peito de frango considerada pálida e normal são mostrados na Tabela 3. Os resultados desta tabela mostram que não foi possível encontrar diferenças significativas $(p>0,05)$ para a coloração dos hambúrgueres elaborados com carne pálida e normal em todos os períodos avaliados para os teores de $\mathrm{L}^{\star}$ (luminosidade), $\mathrm{a}^{\star}$ (vermelho) e $\mathrm{b}^{\star}$ (amarelo), exceto para o valor de $\mathrm{L}^{\star}$ analisado com 120 dias de estocagem, em que foram observadas diferenças significativas $(\mathrm{p} \leq 0,05)$ entre os hambúrgueres elaborados com carne pálida, que apresentaram maior valor de $L^{\star}(64,83)$, e os elaborados com carne normal $(61,32)$.

Os dados de cor desta tabela sugerem que a elaboração de hambúrgueres com carne de peito pálida não causam prejuízos na coloração do produto final, sendo que a cor é, provavelmente, o principal atributo de qualidade que leva o consumidor a decidir pela aquisição de determinado produto (MONAHAN et al.,

Tabela 2. Faixa etária dos provadores que participaram da análise sensorial do filé empanado.

\begin{tabular}{lccccc}
\hline & \multicolumn{5}{c}{ Faixa etária } \\
\cline { 2 - 6 } & $\begin{array}{c}18 \text { a } 20 \\
\text { anos }\end{array}$ & $\begin{array}{c}21 \text { a } 30 \\
\text { anos }\end{array}$ & $\begin{array}{c}31 \text { a } 40 \\
\text { anos }\end{array}$ & $\begin{array}{c}41 \text { a } 50 \\
\text { anos }\end{array}$ & $\begin{array}{c}51 \text { a } 60 \\
\text { anos }\end{array}$ \\
\hline $\begin{array}{l}\text { Número de } \\
\text { provadores }\end{array}$ & 4 & 22 & 7 & 4 & 2 \\
\hline
\end{tabular}


1994; LIU et al., 1995; SANDERS et al., 1997). Segundo O’Sullivan et al. (2004), o valor L* dos hambúrgueres elaborados com carne de frangos foi de aproximadamente 50, ligeiramente mais baixo que o obtido neste trabalho.

Tabela 3. Coloração $\left(\mathrm{L}^{*}, \mathrm{a}^{*} \mathrm{e} \mathrm{b}^{\star}\right)$, Encolhimento por Fritura (EF), TBA, Perda de Peso por Cozimento (PPC), Força de Cisalhamento (FC) e contagem de microorganismos psicrotróficos (Micro) entre hambúrgueres elaborados com carne de peito de frango considerada pálida e normal.

\begin{tabular}{|c|c|c|c|c|c|c|c|c|}
\hline Parâmetro & $\mathrm{L}^{*}$ & $\mathrm{a}^{*}$ & $\mathrm{~b}^{*}$ & $\mathrm{EF}(\%)$ & TBA & PPC (\%) & $\mathrm{FC}\left(\mathrm{kgf} / \mathrm{cm}^{2}\right)$ & $\begin{array}{c}\text { Micro } \\
\left(\text { Log UFC. } g^{-1}\right)\end{array}$ \\
\hline Pálida & & & & & & & & 6,69 \\
\hline \multicolumn{9}{|c|}{ Período - 7 dias } \\
\hline \multicolumn{9}{|l|}{ Carne } \\
\hline $\mathrm{CV}$ & 3,0433 & 16,8441 & 12,8435 & 22,0574 & 13,8729 & 5,2130 & 7,0628 & \\
\hline $\mathrm{P}$ & 0,5212 & 0,5208 & 0,1962 & 0,4904 & 0,9750 & 0,6797 & 0,0262 & \\
\hline \multicolumn{9}{|c|}{ Período - 30 dias } \\
\hline \multicolumn{9}{|l|}{ Carne } \\
\hline Pálida & 65,47 & 2,76 & 16,95 & 12,49 & 1,38 & 26,52 & 1,27 & 4,80 \\
\hline \multicolumn{9}{|c|}{ Período - 60 dias } \\
\hline \multicolumn{9}{|l|}{ Carne } \\
\hline Pálida & 66,06 & 2,46 & 16,28 & 11,61 & 1,41 & $28,03 \mathrm{a}$ & $1,31 \mathrm{~b}$ & 4,80 \\
\hline Controle & 66,04 & 2,97 & 16,78 & 10,14 & 1,40 & $20,21 \mathrm{~b}$ & $1,85 \mathrm{a}$ & 4,99 \\
\hline $\mathrm{CV}$ & 2,6774 & 9,4982 & 8,5981 & 14,2317 & 2,0462 & 4,3153 & 13,7581 & \\
\hline $\mathrm{P}$ & 0,9931 & 0,0726 & 0,6983 & 0,1737 & 0,8771 & 0,0008 & 0,0379 & \\
\hline \multicolumn{9}{|c|}{ Período - 90 dias } \\
\hline \multicolumn{9}{|l|}{ Carne } \\
\hline Pálida & 65,88 & 2,21 & 17,2967 & 12,528 & $5,2809 a$ & 25,757 & 1,2933 & 4,56 \\
\hline Controle & 65,827 & 2,48 & 18,5867 & 10,654 & $2,6278 \mathrm{~b}$ & 23,340 & 1,73 & 4,91 \\
\hline $\mathrm{CV}$ & 2,5259 & 13,0221 & 6,5752 & 14,9343 & 6,1487 & 7,741 & 15,6917 & \\
\hline \multicolumn{9}{|c|}{ Período - 150 dias } \\
\hline \multicolumn{9}{|l|}{ Carne } \\
\hline Pálida & 63,313 & 2,0033 & 13,8233 & 11,662 & $8,8974 a$ & 30,94 & 1,95 & 4,65 \\
\hline Controle & 61,727 & 2,49 & 14,1067 & 11,828 & $8,084 \mathrm{~b}$ & 29,407 & 1,90 & 4,70 \\
\hline $\mathrm{CV}$ & 2,6214 & 10,7855 & 5,9621 & 10,3758 & 6,5214 & 8,8572 & 9,5787 & \\
\hline $\mathrm{P}$ & 0,3014 & 0,0697 & 0,6820 & 0,8349 & 0,3930 & 0,5210 & 0,7565 & \\
\hline \multicolumn{9}{|c|}{ Período - 180 dias } \\
\hline \multicolumn{9}{|l|}{ Carne } \\
\hline Pálida & 61,287 & $1,5433 \mathrm{~b}$ & 18,3667 & 11,066 & $5,0194 \mathrm{a}$ & 32,353 & 1,9267 & 4,53 \\
\hline Controle & 61,383 & $2,5033^{\mathrm{a}}$ & 18,1133 & 11,522 & $3,8936 b$ & 27,173 & 2,1733 & 4,94 \\
\hline $\mathrm{CV}$ & 2,4274 & 20,7715 & 2,8418 & 8,789 & 10,9431 & 7,6804 & 9,5507 & \\
\hline $\mathrm{P}$ & 0,9404 & 0,0489 & 0,5402 & 0,4883 & 0,0025 & 0,0501 & 0,1977 & \\
\hline
\end{tabular}

Médias seguidas de letras diferentes na coluna diferem entre si $(\mathrm{p}<0,05)$ pelo teste $F$. Sendo, $\mathrm{CV}=$ coeficiente de variação; e $\mathrm{P}=$ nível de significância. 
A Tabela 4 mostra a equação da análise de regressão, coeficiente de determinação $\left(\mathrm{R}^{2}\right)$, Coeficiente de Variação $(\mathrm{CV})$ e Nível de Significância (NS) para os parâmetros de cor objetiva, Encolhimento por Fritura (EF), TBA, Perda de Peso por Cozimento (PPC) e Força de Cisalhamento (FC) dos hambúrgueres elaborados com carne de peito de frango considerada pálida e normal estocados até 180 dias.

Com relação ao parâmetro cor, foram encontradas diferenças significativas $(\mathrm{p} \leq 0,05)$ nas análises de variâncias para os valores de $\mathrm{L}^{\star} \mathrm{e} \mathrm{b}^{\star}$ dos hambúrgueres elaborados com carne normal, e para os valores de $\mathrm{a}^{\star}$ dos elaborados com carne pálida. Os resultados da análise de regressão para os valores de $L^{\star}, a^{\star}$ e $b^{\star}$ apresentaram o comportamento cúbico. Estes resultados revelam que os valores de $\mathrm{L}^{*} \mathrm{e} \mathrm{b}^{\star}$ dos hambúrgueres elaborados com carne normal tendem, primeiramente, a aumentar com o tempo de estocagem, sofrem uma leve queda e, em seguida, se elevam novamente. Para o valor $\mathrm{a}^{\star}$, a análise de regressão também apresentou comportamento cúbico. Isto representa que o teor de vermelho dos hambúrgueres elaborados com carne pálida diminuiu com o tempo de estocagem, apresentou um ligeiro aumento e voltou a cair até o fim do período de estocagem.

Para as análises de Perda de Peso por Cozimento (PPC), foram observadas diferenças significativas $(\mathrm{p} \leq 0,05)$ somente entre as amostras de hambúrgueres elaborados com carne de peito de frango pálida e normal no segundo mês pós-processamento, sendo que as amostras produzidas com carne pálida obtiveram a maior média de porcentagem de PPC $(28,03)$ quando comparadas às dos hambúrgueres elaborados com carne normal $(20,21)$. Estes dados indicam que a carne de peito de coloração pálida não causou prejuízos no parâmetro PPC, quando comparado ao de hambúrgueres elaborados com carne normal.

Foi observada diferença significativa $(\mathrm{p} \leq 0,05)$ para a análise de variância, sendo que, na regressão do parâmetro de PPC, para os hambúrgueres elaborados com filés pálidos, a curva da PPC se comportou de forma linear, diminuindo com o tempo de estocagem. A análise de regressão para os hambúrgueres elaborados com filés de coloração normal mostrou que a PPC se comportou de forma cúbica, com ligeira queda, seguida de um breve aumento e, em seguida, nova diminuição conforme aumentou o tempo de estocagem.

Para a avaliação do Encolhimento por Fritura (EF), não foram encontradas diferenças significativas $(p>0,05)$ entre os hambúrgueres produzidos com carne de peito de frango pálida e normal para este parâmetro entre os períodos de estocagem.

Os resultados da FC entre os hambúrgueres elaborados com carne de peito de frango considerada pálida e normal revelaram diferenças significativas $(\mathrm{p} \leq 0,05)$ entre os hambúrgueres elaborados com carne pálida e normal nos períodos de 7, 60 e 120 dias de estocagem pós-processamento, sendo que as amostras produzidas com carne pálida obtiveram menor FC (1,92, 1,31 e 1,46, respectivamente) do que as elaboradas com carne de coloração normal $(2,34,1,85$ e 1,73 , respectivamente). Não foram encontradas diferenças significativas $(\mathrm{p}>0,05)$ para o parâmetro FC entre as amostras elaboradas com carne pálida e normal nos demais pós-processamento dos hambúrgueres.

Foram observadas diferenças significativas $(p \leq 0,05)$ na análise de variância para a FC dos hambúrgueres elaborados com carne pálida e normal, sendo que a análise de regressão dos hambúrgueres elaborados com carne pálida teve comportamento cúbico e os elaborados com carne normal, um comportamento linear. Estes dados indicam que os hambúrgueres elaborados com carne normal apresentaram diminuição na sua FC com o tempo de estocagem, enquanto que os elaborados com carne pálida apresentaram oscilações na FC conforme o período de estocagem.

Foram encontradas diferenças significativas ( $\mathrm{p} \leq 0,05)$ para o parâmetro TBA entre as amostras elaboradas com carne pálida e normal somente a partir de 90 dias de estocagem, sendo que os hambúrgueres elaborados com carne pálida tiveram os maiores valores de TBA $(5,28,7,78,8,89$ e 5,02, respectivamente) quando comparados às amostras processadas com carne normal $(2,63,7,05,8,08$ e 3,89, respectivamente). Para os hambúrgueres elaborados com carne normal, Torres et al. (1998), em seu trabalho acerca da utilização de sal iodado e não iodado na elaboração de hambúrgueres com carne de frango sobre a oxidação lipídica, obtiveram resultados semelhantes aos deste trabalho, em que avaliaram o valor de TBA com zero, $7,30,60$ e 90 dias de estocagem $(0,84,1,40,2,89,2,51$ e 2,57 , respectivamente).

Foram encontradas diferenças significativas $(\mathrm{p} \leq 0,05)$ para a análise de variância da TBA para as amostras elaboradas com carne pálida e normal no período de estocagem. A análise de regressão indicou comportamento cúbico, neste parâmetro avaliado, para os produtos elaborados, tanto com carne pálida quanto para a carne normal nos períodos de estocagem.

A avaliação microbiológica para pesquisa de bactérias aeróbias psicrotróficas foi realizada com o filé in natura, após 24 horas post-mortem, imediatamente antes do início do processamento para a elaboração dos hambúrgueres. A avaliação foi conduzida com 7 dias após a elaboração dos hambúrgueres (período para equalização dos produtos) bem como a cada mês, até 180 dias de estocagem. Observou-se que há maior contagem de bactérias psicrotróficas nos filés in natura. Após o processamento, esta contagem diminui, demonstrado pelos valores apresentados com 7 dias de pós-processamento, e volta a se elevar nos meses seguintes. Houve maior crescimento de bactérias psicrotróficas nos hambúrgueres elaborados com filés de coloração normal do que nos de coloração pálida nos primeiros meses de estocagem, diminuindo drasticamente com 120 dias de armazenamento e voltando a subir após este período, permanecendo com contagens mais altas. Estes resultados estão um pouco acima dos encontrados por Carvalho et al. (2005) que avaliaram a contagem de psicrotróficos em hambúrgueres disponíveis comercialmente e obtiveram resultados abaixo dos encontrados neste trabalho, com valores máximo e mínimo de 2,6 e 1,2 , respectivamente.

Com 7 dias de estocagem dos hambúrgueres, foi realizada a análise sensorial dos produtos utilizando-se o teste Duo-Trio, em que foram servidas aos provadores uma 
Tabela 4. Equação da análise de regressão, coeficiente de determinação $\left(\mathrm{R}^{2}\right)$ e Coeficiente de Variação (CV) e Nível de Significância (NS) para o parâmetro de cor $\left(\mathrm{L}^{*}, \mathrm{a}^{*} \mathrm{e} \mathrm{b}^{*}\right.$ ), Encolhimento por Fritura (EF), Perda de Peso por Cozimento (PPC), TBA e Força de Cisalhamento (FC) dos hambúrgueres elaborados com filés de peito de frango de corte considerados pálido e normal.

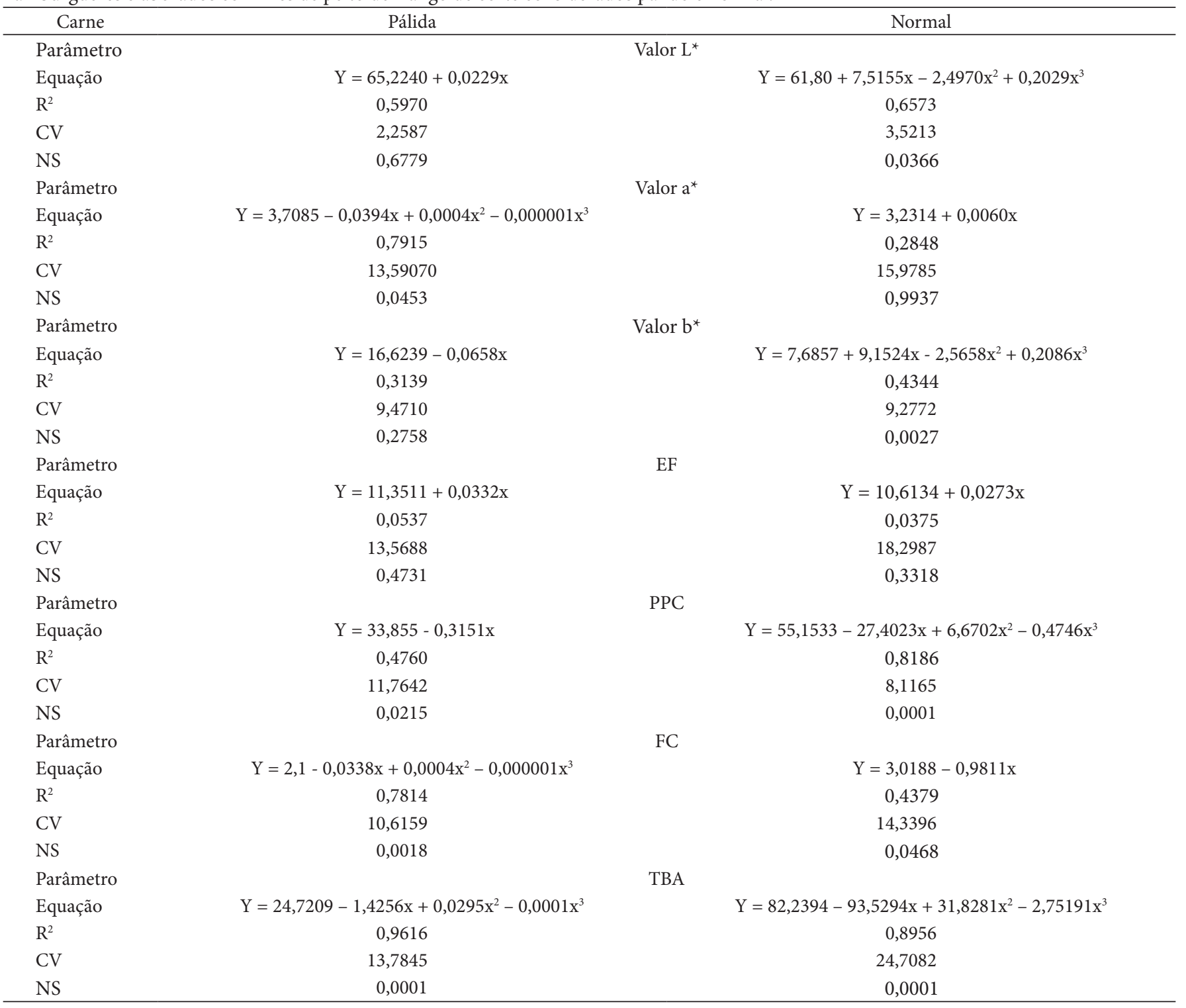

amostra de cada tratamento e uma referência. Este teste se baseia na tentativa de identificação de qual das amostras é idêntica à referência.

Para este teste, foi utilizado um total de 48 provadores. O número mínimo de respostas corretas para estabelecer diferença significativa $(\mathrm{p} \leq 0,05)$ entre as amostras testadas foi igual a 31 . Como o número de respostas corretas foi 27 , número menor que o número mínimo de respostas corretas para estabelecer diferença significativa, conclui-se que não há diferença significativa entre as amostras ao nível de significância de 5\%.

Não foi possível discutir os resultados obtidos com dados da literatura, pois, de acordo com as bases de dados pesquisadas, não foram encontrados trabalhos referentes ao tipo de carne pesquisada (peito de frango de corte de coloração pálida) para o processamento de hambúrgueres.

\subsection{Filés de peito empanados}

Antes das análises de qualidade dos filés de peito de frango empanados, foi obedecido o tempo de 7 dias de espera para equalização dos produtos que foram armazenados à temperatura de $-17^{\circ} \mathrm{C}$. Os resultados da análise de TBA e contagem de microorganismos psicrotróficos entre os filés empanados elaborados com carne de peito de frango considerada pálida e normal são mostrados na Tabela 5. Foram encontradas diferenças significativas ( $\mathrm{p} \leq 0,05)$ entre os filés empanados produzidos com carne pálida e normal para o parâmetro de valor TBA somente nos períodos de 120 e 150 dias de estocagem, sendo que os filés empanados produzidos com carne de peito de coloração pálida tiveram os menores valores de TBA $(2,97$ e 3,61 , respectivamente) quando comparados aos filés elaborados com carne normal (3,21 e 3,66, respectivamente). Estes dados 
mostram que a carne de peito de coloração pálida pode ser utilizada na elaboração de filés empanados sem causar prejuízos na estabilidade lipídica das amostras armazenadas até o período máximo de estocagem avaliado (180 dias).

Tabela 5. Análise de valor TBA, rancidez e contagem de microorganismos psicrotróficos entre os filés empanados elaborados com carne de peito de frango considerada pálida e normal.

\begin{tabular}{|c|c|c|}
\hline Parâmetro & TBA & Psicrotróficos (Log UFC.g $\left.{ }^{-1}\right)$ \\
\hline \multicolumn{3}{|c|}{ Período - zero } \\
\hline Pálida & & 5,48 \\
\hline Controle & & 4,90 \\
\hline \multicolumn{3}{|c|}{ Período - 7 dias } \\
\hline \multicolumn{3}{|l|}{ Carne } \\
\hline Pálida & 2,72 & 3,29 \\
\hline Controle & 3,37 & 3,46 \\
\hline $\mathrm{CV}$ & 45,3270 & \\
\hline \multirow[t]{2}{*}{$\mathrm{P}$} & 0,4216 & \\
\hline & Períc & 30 dias \\
\hline \multicolumn{3}{|l|}{ Carne } \\
\hline Pálida & 4,41 & 3,10 \\
\hline Controle & 4,45 & 3,05 \\
\hline $\mathrm{CV}$ & 13,3332 & \\
\hline \multirow[t]{2}{*}{$\mathrm{P}$} & 0,9011 & \\
\hline & Períc & 50 dias \\
\hline \multicolumn{3}{|l|}{ Carne } \\
\hline Pálida & 4,67 & 2,87 \\
\hline Controle & 4,92 & 3,28 \\
\hline $\mathrm{CV}$ & 5,2241 & \\
\hline \multirow[t]{2}{*}{$\mathrm{P}$} & 0,1147 & \\
\hline & Períc & 0 dias \\
\hline \multicolumn{3}{|l|}{ Carne } \\
\hline Pálida & 4,66 & 3,63 \\
\hline Controle & 4,92 & 3,80 \\
\hline $\mathrm{CV}$ & 5,0963 & \\
\hline \multirow[t]{2}{*}{$\mathrm{P}$} & 0,0944 & \\
\hline & Perío & 20 dias \\
\hline \multicolumn{3}{|l|}{ Carne } \\
\hline Pálida & $2,97 b$ & 3,28 \\
\hline Controle & $3,21^{\mathrm{a}}$ & 3,44 \\
\hline $\mathrm{CV}$ & 4,4301 & \\
\hline \multirow[t]{2}{*}{$\mathrm{P}$} & 0,0114 & \\
\hline & Perío & 50 dias \\
\hline \multicolumn{3}{|l|}{ Carne } \\
\hline Pálida & $3,21 b$ & 3,10 \\
\hline Controle & $3,66^{\mathrm{a}}$ & 3,14 \\
\hline $\mathrm{CV}$ & 6,1392 & \\
\hline \multirow[t]{2}{*}{$\mathrm{P}$} & 0,0039 & \\
\hline & Perío & 80 dias \\
\hline \multicolumn{3}{|l|}{ Carne } \\
\hline Pálida & 3,40 & 3,49 \\
\hline Controle & 3,23 & 3,43 \\
\hline $\mathrm{CV}$ & 12,9766 & \\
\hline $\mathrm{P}$ & 0,5075 & \\
\hline
\end{tabular}

A avaliação microbiológica para pesquisa de bactérias aeróbias psicrotróficas, como a realizada para os filés empanados, foi efetuada também com o filé in natura após 24 horas postmortem, imediatamente antes do início do processamento para a elaboração dos filés empanados. A avaliação foi conduzida também 7 dias após a elaboração dos hambúrgueres (período para equalização dos produtos) bem como a cada mês, até 180 dias pós-processo.

Observa-se que há maior contagem de bactérias psicrotróficas nos filés in natura. Após o processamento, os filés empanados produzidos com carne de peito de frango de coloração normal e pálida apresentaram comportamentos semelhantes no decorrer do período de armazenamento. Para os filés elaborados com carne de peito de frango pálida, a contagem de bactérias psicrotróficas diminui, demonstrado pelos valores apresentados com 7 e 30 dias, e volta a aumentar com 60 dias de estocagem.

Carvalho et al. (2005), que avaliaram a contagem de psicrotróficos em filés empanados disponíveis comercialmente, obtiveram resultados mais elevados que os deste trabalho, com valores máximo e mínimo de 4,0 e 1,4, respectivamente.

Não foi possível discutir os resultados obtidos com dados da literatura, pois, de acordo com as bases de dados pesquisadas, não foram encontrados trabalhos referentes ao tipo de carne pesquisada (peito de frango de corte de coloração pálida) para o processamento de filés empanados.

\section{Conclusões}

A carne de peito de frango de coloração pálida pode ser utilizada como matéria-prima para a elaboração de hambúrgueres e filés empanados sem causar prejuízos na sua qualidade e sabor. Para os filés empanados, não foram encontradas diferenças nos parâmetros de TBA e avaliação microbiológica nos períodos de armazenamento estudados entre os dois tipos de carne. Os hambúrgueres elaborados com carne de peito de frango pálida $\mathrm{e}$ normal não diferiram nos parâmetros avaliados de cor objetiva, encolhimento por fritura, perda de peso por cozimento e microbiologia nos períodos de armazenagem avaliados. Mas apresentaram prejuízos na força de cisalhamento nos períodos de 7, 60 e 120 dias e na análise de TBA com 90 a 180 dias de estocagem.

\section{Referências bibliográficas}

CARVALHO, A. C. F. B. et al. Presença de microrganismos mesófilos, psicrotróficos e coliformes em diferentes amostras de produtos avícolas. Arquivos do Instituto de Biologia, v. 72, n. 3, p. 303-307, jul./set. 2005.

HONIKEL, K. O. Influence of chilling on meat quality attributes of fast glycolysing pork muscles. In: Evaluation and control of meat quality in pigs. Tarrant, P. V.; Eikelenboom, G.; Monin, G. (Eds.). Dordrecht: Martinius Nijhoff, 1987. p. 273-283.

LI, W. et al. Sodium tripolyphosphate stability and effect in ground turkey meat. Journal of Food Science, v. 58, n. 3, p. 501-504, 1993.

LIU, Q.; LANARI, M. C.; SHAEFER, D. M. A review of dietary vitamin E supplementation for improvement of beef quality. Journal Animal Science, v. 73, n. 10, p. 3131-3140, 1995.

MONAHAN, F. J. et al. Effect of oxidized dietary lipid and vitamin E on the colour stability of pork chops. Meat Science, v. 37, n. 2, p. 205-215, 1994. 
O'SULLIVAN, C. M. et al. Assessment of the Antioxidant Potential of Food Ingredients in Fresh, Previously Frozen and Cooked Chicken Patties. International Journal of Poultry Science, v. 3, n. 5 , p. 337-344, 2004.

SANDERS, S. K. et al. Vitamin E supplementation of cattle and shelflife of beef for the japanese market. Journal Animal Science, v. 75, n. 10, p. 2634-2640, 1997.

SAS Institute Inc. SAS /STAT Guide for personal Computers. Version 6.0. Cary, NC., 1998.

SILVA, N.; JUNQUEIRA, V. C. A.; SILVEIRA, N. F. A. Contagem total de microrganismos aeróbios mesófilos, aeróbios psicrotróficos e bolores e leveduras em placas. In: Manual de Métodos de Análise Microbiológica de Alimentos. São Paulo: Livraria Varela, 1997. p. 21-29.

SQUIRES, E. J. et al. Reseach note: Utility of the thiobarbituric acid test in the determination of the quality of fels and oils in feeds. Poultry science, v. 70, n. 1, p. 180-183, 1991.
STONE \& SIDEL, J. L. Sensory evaluation practices. New York/ London: Academic Press Inc., 1985.

TARLADGIS, B. G.; WATTS, B. M.; YOUNATHAN, M. T. A distillation method for the quantitative determination of malonaldehyde in rancid foods. The Journal of the American Oil Chemist' Society, v. 37, n. 1, p. 44-48, 1960.

TORRES, E. A. F. S. et al. Papel do sal iodado na oxidação lipídica em hambúrgueres bovino e suíno (misto) ou de frango. Ciência Tecnologia Alimentos, v. 18, n. 1, p.49-52, Jan./Apr. 1998.

Van LAACK, R. L. J. M. et al. Characteristics of pale, soft, exudative broiler breast meat. Poultry Science, v. 79, n. 7, p. 1057-1061, 2000.

WINCKE, W. Direst determination of the thiobarbituric acid value in trichloroacetic of the fish as a measure of oxidative rancidity. Fette Seifen Anstrichmittel, v. 72, p. 1084-1087, 1970. 